\title{
Emotions, Social Activity and Neuroscience: The Cultural-Historical Formation of Emotion
}

\begin{abstract}
This article challenges the use of cognitive-behavioural psychological models underpinning many of the dominant and popular accounts of emotion in the neurosciences. Acknowledging that neurobiology is important for any understanding of emotion, an alternative model of neuropsychology is sought in the work of theorists of the cultural-historical school, particularly A. N. Leontyev and A. R. Luria. The importance of their work in stressing the key role of intentional social activity, culture, and language in the formation of human neuropsychological functions is developed into a theory of emotions that can provide an alternative for emotion studies. In this theory, activity, culture, history, and individual ontogeny play the defining role in structuring the neurobiological systems that underlie emotions, as opposed to the evolution of behaviours that are hard-wired into the brain and function as automatic responses. Instead, it is understood that there is a continuum between evolution and human social and cultural development.
\end{abstract}

Keywords: social activity; emotion; neuroscience; cultural-historical school; signs; language. 


\section{Introduction}

In recent years a growing body of literature has started to develop positive criticisms of neuroscience, suggesting alternative conceptual models of the brain that seek to influence the impact of neuroscience on psychology. In particular, these critical alternatives are concerned with what neuroscience tends to ignore - the role that culture and social activity plays in shaping the neurobiology of the brain (Kitayama and Uskul, 2011; Choudhury and Slaby, 2012). As Choudhury and Slaby say in the introduction to their edited collection Critical Neuroscience, 'the goal is to work towards an integrated approach to behaviour that situates the brain and cognition in the body, the social milieu, and the political world' (2012, p. 3). I aim to contribute to that goal here, but with specific reference to the influence neuroscience has had on the understanding of emotions. In developing an alternative approach to neuroscience than that contained in many contemporary studies of emotion, I draw on the relatively neglected work of the cultural-historical school, especially A. N. Leontyev and A. R. Luria. Influenced by the thinking of Vygotsky (1987), both Leontyev (1981) and Luria (1966; 1973) always maintained that social activity, especially in the form of labour and linguistic communication, played an essential part in the formation of human consciousness and emotion. Their view was that the neurobiological and neuropsychological formation of consciousness in organisms is based on their activity, and that in humans the 'higher' psychological processes are formed in activity mediated by tool use. The category of 'tools', however, includes not only instruments fashioned to transform nature, but also signs that are used in social communication - symbols, images, words, and other artefacts that compose 
human language and culture - and which reform human neuropsychology. This has profound implications for our understanding of consciousness and emotion. Here, I will use this theoretical framework to create an understanding of emotion as historically and culturally developed, as is the neurobiological patterning of the brain on which thinking and feeling is dependent, but by which it is not determined. Before I do this, though, I will briefly consider some accounts of emotions in the neurosciences that I am contrasting this theory with.

\section{Neuroscience and the Evolution of Emotion}

One powerful and popular strand of thinking in neuroscience understands emotion as generated by neural systems that have formed in humans and other species throughout the course of their evolution (LeDoux, 1999; Lang, 2014). For these thinkers, attempts to understand the phenomenal experience of emotions in humans - say, for example, the feeling of fear with its raised heartbeat, sweaty hands, and desperate desire to escape - is a red herring, as emotion is generated by brain mechanism that have detected the object of emotion and begun to produce its behavioural response before we are aware of feeling anything. Thus emotion is the result of the initially unconscious processing going on in brain systems, while feeling is the conscious awareness of emotion that arises only in certain circumstances (LeDoux, 1999; Damasio, 2000). Emotions, then, are produced by brain mechanisms or systems that have evolved for survival and are connected to the homeostatic regulation of the body. Cognitive processes can also trigger the brain mechanisms that generate emotions, as they provide 
signals or thoughts that act as stimuli, just as emotionally relevant signals in the environment do. Cognition also allows humans some leeway for conscious agency, as it gives us the capacity to attempt to regulate emotion or decide what to do after we have consciously become aware of our feelings, but it is not the source of emotion itself.

This behavioural and cognitive model of emotion shows up most strongly in Damasio's work. Here, the emotionally competent stimuli, which trigger the homeostatic regulatory neural mechanisms that produce emotional responses, can come from three sources: 1) the external 'environment'; 2) the visceral inside of the body, as in the way low blood sugar levels may cause hunger; or 3) 'from the "mental” inside' (Damasio, 1995, p. 117), say, from the mental representation of a threating object or situation that causes fear. Thus for Damasio, as for LeDoux, emotions are largely behavioural responses instigated by innate brain mechanisms that are triggered automatically with the appearance of the competent environmental or cognitive stimulus. In Damasio's (1995) early work, the distinction between 'primary emotions', which are largely innate and appear in early infancy, and 'secondary emotions' that emerge in adult life, seemed to allow for the possibility of learning and cultural variation of the emotions. However, he later claimed that secondary emotions are also largely pre-set by biology, so that 'notwithstanding the reality that learning and culture alter the expression of emotions and give emotions new meanings, emotions are biologically determined processes, depending on innately set brain devices, laid down by a long evolutionary history' (Damasio, 2000, p. 51). 
Because of this, a wide range of living organisms have emotions, including relatively simple ones that lack the brain regions and functions to experience or realise that they are having an emotion - in Damasio's terms, to feel the emotion. Instead, 'all they require is a simple perceptual apparatus - a filter to detect the emotionally competent stimulus and the capacity to emote': which is, 'to respond to them [the stimuli] with an emotion' (Damasio, 2004, p. 50).

However, one of the central problems with this understanding of emotions in neuroscience is the lack of recognition of the social, cultural and historical world within which the human species acts. As the neuroscientist Steven Rose has pointed out, because the human brain is thought to have taken on its modern form in the Pleistocene period, probably around 250,000 years ago, many neurobiologists and evolutionary psychologists assume that little of fundamental importance has changed since. Thus, behavioural patterns laid down then and hardwired into the brain - including emotional responses - remain essentially the same today upon encountering the required stimulus. Yet this ignores the fundamental importance of cultural history and the unique development of each individual within history and society (Rose, 2005; 2006). If we take this seriously it means, for Rose, that many 'brain mechanisms' are not innate and unchanging, but that...

...during development certain critical or sensitive periods occur during which the brain is specifically primed to respond to environmental context and in doing so to acquire particular capacities or behaviours. 
During such periods particular relevant brain regions exhibit great plasticity, modifying their structure and connectivity in response to experience - for example, visual or linguistic (Rose, 2006, p. 115).

Rose goes on to say that depending on the culture, different behaviours are developed in children and at different times of life, requiring varied skills and capacities that only emerge in particular cultural contexts. Within these contexts, synaptic connections of the brain are moulded, sharpened, or pruned away as children act in response to the external social world, especially through the guidance of, and engagement with, other people. Furthermore, human thought and activity can change without corresponding changes in neurobiology, as in the way consciousness has been fundamentally altered by science, art, and politics, changing not only the way we think about the world but also the way we act within it. From my perspective here, this means that other forms of behaviour, such as the emotional, is also fundamentally altered by culture and history.

For a neuroscientist like Damasio, however, everything is centred on the embodied brain, which is understood not only to induce emotion but also to produce conscious thoughts by manipulating mental imagery. Beyond the brain there seems to be little more than a collection of stimuli that compose the external 'environment', but nothing that resembles a meaningful social and historical world in which humans act intentionally. It is this latter milieu that concerned the thinkers of the cultural-historical school in their attempt to situate 
evolutionary neurobiological changes within the context of activity in a world that is, for humans, social and cultural.

\section{The Evolution of the Brain in Activity: Mind, Consciousness and Emotion}

One of the central tenets that links the thinking of a modern neuroscientist like Rose with the earlier thinking of activity theorists such as Leontyev and Luria, is a resistance to reducing the 'mind' or consciousness to the internal workings of the brain, separated from the activity of humans in the world. Instead, the 'mind' is seen as inseparable from activity, which relates us to the things and objects of interest in the social world, and the emotions are also integral to this. However, activity has a specific meaning to the thinkers of the cultural-historical school, such as Leontyev. Following Marx and Engels (1970), human activity is understood as structured by the social relations humans enter into to produce the means of subsistence, satisfying our needs (which thereafter become historical needs). The tools that human groups create in order to produce are the medium through which we are related to, and gain a degree of mastery over, objects and nature. Alongside these, signs and language are the tools and the medium through which we organise social relations and activities. It must be noted at this point, though, that the term 'language' means something very specific to members of the cultural-historical school. As Bruner points out, for Vygotsky and those influenced by him, language is not to be understood in Saussure's (1974) terms as a system of signs, but instead language is a powerful system of tools for use - initially in speech, 'but increasingly and once 
inwardness is achieved, in perception, in memory, in thought and imagination' (Bruner, 1987, p. 15). As Leontyev (1981) puts it, language is the store for humankind's socio-historical experience of practice - an array of symbolic meanings - but speech is the use of language as a tool of communication that changes both human activity and neuropsychology. Thus, tool and language use are the two mediums of human relations and interactions, and it is through these activities that we appropriate the social heritage psychologically. As Leontyev says;

A tool mediates activity that connects a person not only with the world of objects but also with other people. This means that a person's activity assimilates the experience of humanity. It means that a person's mental processes (the 'higher mental functions') acquire a structure necessarily linked to socio-historically formed means and modes, which are transmitted to him by other people through team-work and social intercourse. But to transmit a means or a mode for carrying out some process can be done only in external form - in the form of action or in the form of external speech. In other words, the higher and specifically human processes can arise only through mutual interaction of person with person, as interpsychological processes, which only later come to be carried out by the individual independently (Leontyev, 1972, p. 19, emphasis in original). 
For the cultural-historical school, then, the notion of 'culture' also has a very different meaning from that expressed today in some branches of cultural neuroscience. For example, Kitayama and Uskul (2011) define culture 'in terms of values (general goal states) and practices (behavioural routines often designed to achieve the values) that are collectively distributed and, to some important extent, shared' (p. 421). These practices entail scripted behavioural sequences that can powerfully shape and modify brain pathways, accumulating the effects of cultural experience. In contrast to this, as Ratner (2000) points out, for the cultural-historical school, culture consists in practical, socially organised activity, so it is not confined to the more traditional definitions of culture involving values and beliefs. And as Leontyev (1981) shows, this activity centres on labour and language that is socially meaningful, forming interpsychological processes that become intrapsychological. It is this social activity and the historical consciousness it creates that shapes the neural interconnectivity of the brain and nervous system through the development of each individual.

This is important for the understanding of emotion, because for Leontyev emotional experience only emerges in historical activity with the development of the human mind. Here, emotions are 'crystallised' in the object of emotional experience so that every act takes on an emotional colouring. Although the emotions are crystallised externally and objectively in actions, interactions, and social relations, they become 'motives-stimuli' for individual persons (Leontyev, 1978). This is different from the stimulus-response model fundamental to cognitive-behavioural theories of emotion, because in activity theory the motives for specific actions are part of an overall pattern of social relations and activities 
that have a symbolic or linguistic meaning for participants. Therefore, behaviour is not understood as generated by forces of cause and effect, but instead activity is motivated through social meanings and intentional activity. This does not mean that the motives-stimuli, including emotions, must be consciously articulated or aimed at a specific goal. It means that the motives-stimuli find their psychical reflection in the emotional colouring of the act. A practical example of Leontyev's theory of emotion can be seen in Roth's (2007) study of workers at a salmon hatchery. This illustrates how actions performed by workers in their jobs expresses emotion, identity, and practical reasoning. However, this only has meaning and sense in terms of the goals of the overall unit of activity within the workplace to which specific actions, and feelings, are oriented.

Given this, the ideas of the cultural-historical school have implications for the understanding of the behaviour of other animals and organisms, in terms of whether or not they have emotions. For Leontyev (1981) the simplest living organisms exhibit irritability in relation to their environment, which is to say they respond in some way to certain elements in their milieu. This is true of even the most basic organisms that, as Damasio (2004) said, have merely a simple perceptive filter to detect elements in their environment. However, for Leontyev, their responses are not emotions, nor at this stage are they even to be thought of as sensations. Sensitivity only arises in more complex organisms that have some awareness of what they are sensitive to. Following this, the awareness of separate sensations comes even later, with organisms whose sensitivity has become differentiated because their activity is more complex. For example, a 
more complex life form like a frog becomes sensitive to certain sounds in its lifeworld, like rustling grass, which may indicate the movement of an insect that can provide a meal. Even then the sound must be coordinated with other sensations, such as visual cues and movement, before the animal is certain of what the rustling in the grass indicates and how it should respond - is it an insect in the grass that can be eaten or a threat that necessitates avoidance? Sensations, then, are important in orienting the activity of more sophisticated organisms, because they provide a signalling function that adapts activity to the environment.

According to Leontyev (1981) this means that even for those animals whose behaviour is largely instinctive, their activity must always be malleable to some degree in order to adapt to quickly changing environmental conditions or simply to respond to rapidly changing situations. Most of the more highly developed life forms, such as mammals, have some capacity for flexible and learned behaviours that are required by immediate and sometimes unusual or unexpected occurrences. For humans, this is much more the case than in other animals because our behaviour is less reliant on instinct and much more on the technology and language of our culture. This is something that is stored externally in our social heritage and has to be learned and mastered by succeeding generations. For example, a pilot flying an aeroplane does not rely solely on inherited organs of sensitivity to fly the craft, but on invented devices like radar systems in order to navigate course; she must also learn how to use and interpret the information provided by such instruments in order to fly the plane safely to its destination. Additionally, she must communicate with ground staff, such as those in air traffic control, so that the plane can be navigated to its 
destination in coordination with all the other aircraft in the vicinity. To do all this successfully, the pilot has to have sensations like other animals, such as sight, hearing, and touch: however, these sensations are now converted into perception, which is the ability to reflect on the external environment and coordinate a range of sensations and actions in terms of their overall meanings and goals. In humans there also emerges the intellect, which is dependent on the stocks of knowledge needed to perform various operations in human activity. The ability to fly a plane rests on conscious knowledge of geography and navigation techniques, computing, and the mechanics of flight and piloting. Thus, our pilot must master a range of instruments and have knowledge of how to operate and read them. She also must have constant communication with ground staff, co-pilots, cabin crew, and passengers, to fly the plane successfully. This activity is directed and oriented within social relations and mediated by technology and language.

The point I want to make here, using Leontyev's work, is this: in passing from acting in the environment through irritability, then sensation, and then with perception and intellect, organisms go through various stages in the organisation of activity. Life that is organised through irritability and sensation relies to varying degrees on behaviours that have been passed on through the generations by biological hereditary, with some learning involved, whereas human activity is directed by social and cultural goals and relies on assimilation - the learning and mastery of external tools in ontogeny that have been invented by human groups; specifically, technologies and language. In this approach, activity does not operate according to the direct causal relationship between 
stimulus and response but is mediated by tools and signs, and thus is meaningfully oriented towards objects and ends in a social world. Emotion does not belong in the realm of irritability or even in that of sensation, but instead emotion in the human sense of the term emerges in meaningful, linguistic, intentional activity.

To return to our pilot on the aeroplane, she and her crew must also communicate emotionally to the passengers, particularly that all is safe and well and that they are in the hands of skilled professionals who will get them safely to their destination. This involves not only the management of individual emotions (Hochschild, 1983) - the control of rising fear and panic by individual crew members if something seems to be going wrong on the flight - but also the collective management of emotion on the aircraft. By doing this, the crew aim to make passengers feel safe and comfortable on the flight and, even in an emergency, attempt to contain any panic, especially if an evacuation of the craft is possible. Thus, as Roth (2007) showed, the actions of the crew will be coloured by emotion as they play their part in the overall activity of safely flying an aeroplane. In this, their emotions and practical reasoning are integral to the actions necessary to achieve a safe flight, actions which also express the norms of their profession.

But this turns the central idea of reductive neuroscience on its head. From the viewpoint of activity theory, the phenomenal emotions and feelings we have result from our activity in the world, and this structures neurobiology rather than being the result of it. Activity theorists developed this idea when working with patients who had sustained some form of brain damage, noting that in 
having to relearn how to perform many of the activities of everyday life, different regions and functions of the brain would be used to compensate for areas that had been damaged. In other words, brain regions and functions worked together in a larger functional unity to allow humans to perform actions, and when some regions and functions got damaged others would be employed in a new functional unity to allow the person to achieve certain actions and goals. This meant that activity theorists formed a view of the brain very similar to that of modern neuroscientists like Rose (2006), in that neural functioning is seen to depend not on isolated brain functions or systems, but upon how the various systems work together to form larger patterns of neural interconnectivity. As Leontyev puts it, psychic (or mental) functions...

...are not based on the functioning of some isolated group of cortical cells or other, but rather on a complex brain system, whose elements are located in different zones of the brain often far apart, but which, however, form a single constellation (Leontyev, 1981, p. 322).

Furthermore, these neurological systems are formed not simply in an evolutionary sense, according to activity that was happening in the human group hundreds of thousands of years ago, but can be formed and re-formed according to social and historical activity that is current - as in compensation after brain damage, where brain systems can be re-organised to perform activities. Also, as noted by Rose (2006), the consciousness of humans operates not only according 
to biological laws but also to socio-historical ones. This means that 'the brain includes not certain, specially human capacities of some kind or another, but only the capacity to form these capacities' (Leontyev, 1981, p. 154). Thus the capacity to speak a particular language or to know the current science of physical laws is not given by the brain at birth; what is given is the capacity to learn and master such capacities in homes, schools and universities. This is the formation of human consciousness, governed not by pre-set brain processes but by sociohistorical development and, within this, the skills and capacities mastered in the ontogeny of each individual.

For Leontyev, then, and as we will see for Luria too, what is central to the formation of human consciousness - and with it the formation of feeling and emotion - is speech and other symbolic forms of activity, for it is within such forms of communication that historical consciousness is developed.

\section{A. R. Luria: Action, Speech and Emotion}

Luria's $(1966 ; 1973)$ thinking on neuropsychology is shaped by the same influences as Leontyev's, centred on the importance of activity and language, which he contrasts to other approaches in psychology:

The basic difference between our approach and that of traditional psychology will be that we are not seeking the origins of human consciousness in the depths of the 'soul' or in the independently acting 
mechanisms of the brain (where we shall find nothing). Rather, we are operating in an entirely different sphere - in humans' actual relationship with reality, in their social history, which is closely tied to labour and language (Luria, 1981, pp. 27-28).

Again, though, it is important to emphasize that with the term language, Luria is using it in the Vygotskian sense as a system of tools for use, both in speech and as an internal tool for organising human mental processes and coordinating brain functions. In Luria's approach, the brain is seen as a 'working brain', meaning that it is understood to be part of a body located in the world and its function is to achieve tasks - it literally works to achieve the goals of human activity, which are social and historical. We achieve these activities through tools, such as work tools, memory aids, and speech, but these are not just external tools: the mastery and use of them re-shapes brain functions, which are seen as dynamic functional systems that change with development. As with Leontyev, no area or function of the brain is understood as working in isolation; instead they all work as part of an overall system. Speech and other symbolic forms are a key element in this because they are the primary external tools or mediators through which human activity is coordinated and organised in a social and cultural world. Thus, speech is central to the higher mental functions because at the point when it begins to be mastered and internalised in early childhood, it becomes the organising principle not only in human activity but also for mental and neural processes. For example, when we master speech as children, we no longer perceive and remember purely through visual cues, but 
these are now merged with words. We see with words as much as with our eyes because the visual and language centres in the brain are working as a functional unit, which is the result of years of developmental activity. In perceiving objects, say, we do not see shiny things travelling in space, but cars or lorries moving down a road, and we understand the use and meaning of these objects in our society. This shows tools, symbols, and words as...

... external aids or historically formed devices [that] are essential elements in the establishment of functional connections between individual parts of the brain, and that by their aid, areas of the brain which previously were independent become the components of a single functional system ... historically formed measures for the organization of human behaviour tie new knots in the activity of man's brain (Luria, 1973, p. 31, emphasis in original).

These ideas of Luria's have echoes in contemporary theories known as the 'extended mind' thesis (Clark, 2008), in which cognitive processes are not seen as existing simply in the head but are reliant on devices in the environment that enable humans to achieve mental tasks. They are also similar to the 'enactive' approach to cognition and neuroscience, in which cognition is not understood as the representation of sensory information constructed by areas or systems in the brain, but instead is seen in the context of the organism's active engagement with its world (Noë, 2004). Colombetti (2014) has taken this enactive approach to the 
mind and applied it to affect and emotion. In her approach, affect is inextricably bound up with mental processes and both are brought forth in the living organism by virtue of its specific organisation and its interaction with the environment. In this respect there is a great similarity with the work of activity theorists like Leontyev and Luria. Colombetti also understands the interaction of more basic organisms with their world to be based in sensitivity or sensation which she subsumes under the term 'affect' - rather than fully formed emotions. However, where this approach differs from activity theory is that it is based in dynamical systems theory, which understands organisms to be self-organising: that is, in response to organism-environment interactions a complex system such as the neural system and other organic processes - can 'generate and maintain structured order within itself by way of mutual influences among its components' (Colombetti, 2014, p. 55). However, this approach centres on the self-organisation of an individual organism as it interacts with its world. The point that activity theorists are making, especially with respect to a social species like humans whose activities are structured by group organisation and by symbolic communication, is that organic and neural systems come under the direction of social processes and so, at the very most, could only be considered as semi-autonomous systems that are not completely self-organising. Instead, their organisation is directed from outside, extrinsically, from the socio-historical world.

An example from Luria's work is that of movement, which in humans becomes 'voluntary' once it comes under the control of intentional activity organised by speech. This involves what Luria (1973) calls 'kinaesthetic afferentation', which 
is the system of kinaesthetic impulses reaching the brain from the moving limbs. A chain of consecutive movements with a temporal course makes up an action that eventually becomes a single 'kinaesthetic melody' that can be repeated. In many animals these movements are controlled to varying degrees by instinctive behaviours that are determined by inborn programmes, while for humans operating at the level of conscious (if not always self-conscious) action they are dictated by intentions formed within speech and other symbolic systems. Even if these active, intentional movements acquire the automatism of the instincts, as in habits for example, they are still qualitatively different because they are organised by linguistically based, meaningful systems of activity and oriented to goals - what Luria calls a 'kinetic bodily logos'. An example of this in young children would be learning handwriting, a process in which children are first taught to form individual letters on a page, then to join them up into words, and eventually to use this technique freely and spontaneously, expressing them selves in handwriting on a page. Here, a chain of actions is first learned by mastering each action in the chain, then by practising joining up these actions and forming them as a kinaesthetic melody - the ability to spontaneously do handwriting. Once again, though, this is guided by an overall social activity, in this case learning how to communicate using the language of one's culture, a processes in which the action of handwriting is but one part.

Thus, for Luria, the old idea of movement as an act of volition was replaced by behaviourism, which understood behaviour as reflex action formed through the direct causal chain of stimulus and response. However, these models of activity must now be replaced, certainly for humans, by an intentional model of 
voluntary movement or 'motor' task, and this is formed in speech acts. Luria says that 'by fixing the intentions and formulating programmes of activity, speech becomes at the same time a method of regulating behaviour and setting the course of mental processes' (1973, p. 307). For him this means that:

The higher forms of mental processes have a particularly complex structure; they are laid down during ontogeny... As a rule they are based on a series of external aids, such as language, the digital system of counting, formed in the process of social history, they are mediated by them, and cannot in general be perceived without their participation... they are always connected with reflection of the outside world in full activity, and their conception loses all its meaning if it is considered apart from this fact (Luria, 1973, pp. 30-31).

This has profound implications for the understanding of feeling and emotion, for now we can no longer see emotion as operating according to a stimulusresponse mechanism of action and movement. Just as movement is a kinetic bodily logos operating according to intentional activity that is socially and culturally oriented through symbolic and linguistic meanings, so too must feeling and emotion operate in the same way, because all activity and movement has some element of feeling or emotion in it, just as it has an element of reason (Freeman, 2000). And just as all forms of perception and movement are now integrated with language - so that we rarely see or hear anything we cannot 
name, and if we do we immediately struggle to begin to identify it - so too is emotion. Feeling and emotion is part of intentional, linguistically based human activity and cannot be properly understood separately from it. I will fully justify this is the final section here.

However, there are two modifications needed to Luria's work to bring it into line with contemporary research: the first is related to neuroscience, the second to do with the way he conceptualised emotion. First, Luria sees the functional networks of the brain as hierarchical in their structure so that the higher functions tend to take charge of the lower ones, reorganising their functioning. However, in contemporary neuroscience the relation between working units of the brain is not understood as a strict hierarchy. Instead, neuroscientists see brain functioning as involving a 'neural heterarchy', which 'contains the components of hierarchical systems, as higher levels are in continuous communication with lower level systems via intermediate levels, but have the additional capacity to interact over widely separated levels via direct connections' (Norman et al., 2014, p. 120). This means that entirely new systems are formed within the heterarchy creating what Freeman (2000) calls a global dynamic framework. Approaches such as this in contemporary neuroscience have broken down the idea that the brain can be divided into the 'lower' (older) emotional regions and the 'higher' cognitive ones (formed later in evolution). In a neural heterachy the brain regions traditionally viewed as emotional are also involved in cognition, and vice versa (Pessoa, 2008), meaning that the system is one of continual mutual influence and open to restructuring. However, this only strengthens the aims and findings of the cultural-historical school into the way 
that new functional or global dynamic frameworks of neural interconnectivity can be created through engagement in activity. Exploring this style of neuroscience could provide new avenues of research for cultural-historical thinkers.

Second, when it came to his work on emotion Luria (1932) did not learn his own lesson in respect of how other neuropsychological functions - such as perception, memory, and movement - are modulated and changed through symbolic communication and activity. Instead, he saw emotion as a lower level function that needed regulating by the higher functions. Without regulation emotion has a disruptive, pathological effect on the overall psyche. Therefore he understood affective processes as playing a role only in the disturbance of the linguistically organised 'higher' processes of activity, centred on cognitive rational systems of thought. In fact, affect only appears when the normal motor discharge of impulses is disrupted. This comes perilously close to the view rejected by modern neuroscience - that the newer and higher mental functions and neural systems are largely cognitive and rational, while the older systems are more emotional and irrational. Instead, in a neural heterarchy, both lower and higher functions are cognitive and emotional, and are transformed in their functioning when they become part of a new global dynamic system. Towards the end of his book on emotion, Luria does get closer to an understanding of emotion that would be more in line with this, saying that: 
Every symbolic system may be a powerful means of organizing affect. This can be proved by the part that symbolic systems as images have played in the history of culture; they are connected with emotions and widely employed in art, in the theatre, etc., to organize affect (1932, p. 423).

Additionally, Luria did experiments using hypnosis to show 'that the affective behaviour takes on a new structure after the introduction of symbolic forms' (1932, p. 423). This only confirms what Ratner (2000) has to say about the transformation of lower into higher functions through social activity and interaction:

It transforms lower processes into higher psychological functions by (a) dispensing with many natural processes, (b) modifying (pacifying, civilising) certain natural processes by incorporating them into new systems, and (c) generating novel psychological functions which have no natural analogue or basis (p. 24).

And this is the exact point that I want to make here: that feeling and emotion are not simply basic forms of human responses, produced by brain mechanisms that evolved thousands of years ago, but are socially and historically structured under the influence of culturally mediated symbolic and linguistic forms. 
However, I do think that after these criticisms are taken into account, Luria's approach as demonstrated in his work on other neural functions - like perception, memory, and movement - can still be used to show how feeling and emotion is restructured, modulated and created through symbolic and linguistic activity.

\section{Discussion}

One of the key things to be drawn from the work of the cultural-historical school is that emotion is not to be thought of as the expression of a natural response, triggered by an emotionally competent stimulus, but is an expression integral to an action, which takes its meaning and sense from the patterns of activity and social relations in society. As Gergen has said in his own relational understanding of emotions, ' $[\mathrm{t}]$ hey are forms of action that acquire their intelligibility within relationships, and they gain their value from their social use' (2009, p. 103). Developing a similar view within cultural-historical theory, Mahn and John-Steiner (2002) understand emotions as co-constructions within relations and activities. Their research into educational activities shows how building relations of mutual support and trust among students and teachers can create greater confidence in students and help them overcome fear of failure and various anxieties - especially over expressing their ideas in writing. Attention to creating caring and supportive relationships therefore influences how students feel about themselves and their work. However, the influence of this is not generalised for all students, for the relationships and activities are perceived and 
appropriated differently by each person, depending on their own past life experiences - something Vygotsky referred to with the concept perezhivanie (Mahn and John-Steiner, 2002; González Rey, 2012; Fleer et al., 2017). Even then, emotions are integral to actions that take place in social activities.

Thus, as Ratner (2000) says, these socially constructed emotions in humans either modify natural processes by incorporating them into a new socially formed psychological process, or they are new psychological processes that have no natural basis. For example, an emotion such as fear is often represented in terms of the fight/flight reactions that occur as an automatic response upon the perception of a startling occurrence. But as Barbalet (1998) points out, in the social world the source of fear is often the structured insufficiencies of power that leave people feeling vulnerable or at risk, such as fear of losing your job, income, and home. Furthermore, the fear caused by insufficiencies of power has a totally different feel to it than the fight/flight reactions and is not based on these physiological responses. Instead, this form of fear motivates very different actions that are social and political in nature, like people acting collectively to address the sources of vulnerability and shore up their interests and sense of security. In this way, for Barbalet, all the emotions are directly implicated in social action and in agents' transformation of their social world. For example, inequalities of wealth that create insecurity and fear can be challenged through political parties and movements, and trade unions fight for better wages, working conditions, and job security.

Similarly, how emotions are structured and organised by activities mediated by symbolic and linguistic means, can be seen in the way that poets and writers 
create and articulate new emotions such as anxiety and dread. Philosophers and novelists in the mid-twentieth century did much to articulate and make real the sense of anxiety that many felt in the face of war, the threat of nuclear annihilation, and the growing sense of social isolation, especially in urban environments. This was not simply an intellectual or artistic abstraction: an author like Sartre (1965) actually put a physical feeling to alienation and anxiety in his novel Nausea: a sense of sickness and vertigo that comes from the feeling of living in a world that is alien and inhuman. Such existential novels and philosophical works became popular in the 1950s and 60s, picking up on what Raymond Williams (1977) called a 'structure of feeling' - a vague and intangible feeling of social change among people that is given articulation by artists, so that it becomes more concrete and tangible. In this case, anxiety - which is often described as an objectless fear - was given concrete form by writers like Sartre and expressed the structure of feeling of a new generation who were rejecting the way of life of their parents, especially their perceived conformity to established social and political authority and their acceptance of social norms that were felt to be repressive and outmoded, stifling self-expression. A wave of 'kitchen sink dramas' were created in Britain in the late 1950s to express the feelings of 'angry young men', such as John Osborne's Look Back in Anger, in which a central character (usually male) expressed their anger and distress at feeling out of place in their jobs, traditional domestic roles, and the predetermined nature of their future life trajectory.

However, as Sartre's example of nausea shows, socially created emotions have a bodily, feeling element to them because they are integral to actions. Thus, 
Ratner's (2000) cognitive theory of emotion as a schema-based appraisal of situations gives no significance to the embodiment of emotion, assigning this to an unspecified arousal (Holodynski, 2013). Instead, emotions as integral to action always have some element of bodily feeling to them. As Cromby (2007) points out, emotions are themselves feelings, in that we feel anger, joy, shame, or love: it is just that feelings are a broader category that apply also to nonemotional feelings, such as hunger or thirst, and to the bodily feelings that are associated with emotions, like the raised heartbeat and adrenaline rush associated with fear or excitement. William James (1971) claimed that without these bodily feelings our experience of emotion would be a pale shadow, a mere concept of an emotion rather than one we are actually feeling. James also pointed out that all our actions are accompanied by feelings, like for example the expressive utterance we put into words such as 'and', 'if' or 'but'. 'And' can be said with an impatient intonation, as when we are hurrying someone to a conclusion, or with a drawn-out intonation when we are communicating to someone we are about to add something of significance to what we are saying. Feelings, then, are not to be thought of in the way Damasio (2000) conceptualises them, as the conscious awareness of emotions that are induced by brain processes, triggered by the competent stimulus. Rather, feelings are the emergent consciousness of our meaningful relationship to others, to events, objects, or ends within our activities that we articulate in verbal utterances, or in learned bodily gestures and facial expressions. For Dewey (1958), the distinction between feelings and emotions are essentially experiential and linguistic: some experiences we refer to as feelings, such as having a sense of caution or being nervous on an occasion, while others we refer to as emotions, like when we are 
angry, sad, or in love. In this way, both emotions and feelings can be seen as complexes composed of bodily perceptions that are structured and organised by meaningful social activity (Burkitt, 2014).

Thus if we think of emotion not in terms of a behavioural response to a stimuli but, as Luria (1973) said about movement, as an intentional kinetic bodily logos oriented by symbolic social meanings and activities, then it is this that structures both emotion and feeling. Furthermore, as the work of Leontyev showed, it is not simply movement that concerns us in terms of human activity, but operations that allow us to perform particular actions in which both emotion and practical reason are integral (Roth, 2007). Thus feeling and emotion is shaped in activity that expresses both social meanings and the more personal sense of an act. An example of this is the way that Bakhtin (1990) talks about the emotionalevaluative tones contained in a person's utterance or in the stance they take in an action. That is to say, how a person expresses themself in their action or speech always contains an emotional evaluation of things, others, one's own self, or what is happening in the situation, an evaluation that expresses both social and personal value (in Bakhtin's terms it is 'axiological'). An emotionalevaluative utterance, then, is not primarily cognitive but is also bodily, in that it is expressed in tone of voice, facial expressions, gestures, or movements. However, the point I want to make here is that the social and personal meaning that shapes emotion does not simply change the outward expression of a neurobiological hard-wired response, which becomes feeling when it is recognised by consciousness. Rather, social and personal meaning shapes the entirety of emotion and feeling, both bodily and cognitively, as it is formed in 
activity. In a world of symbolic meaning, speech and other bodily acts do not express a prior emotional experience. Instead, social relations, activity, and meaning are the structuring framework in the complex of symbolic and biological forms in which emotion is created.

\section{Conclusion}

What I have been arguing here is that the behavioural and cognitive model of action and emotion found in some contemporary and popular accounts of emotion is no longer sustainable in emotion studies. This is because, historically and globally, human cultures take the lead in reorganising and restructuring bodily sensations into symbolically and linguistically specific feelings and emotions. The latter operate at a different level to the irritability of simple organisms or the sensate actions of life forms whose behaviour is largely inherited. Under the influence of cultural and historical formations the bodily kinaesthetic logos is directed by intentional, meaningful social activity, and, in the process, dynamical brain systems are formed by the use of symbols and language in activity. Emotion is therefore not primary in all organisms. Instead, irritability becomes sensation in the more complex activity of certain organisms as they adapt to a more variable environmental niche, leading organisms themselves to become more complex with more defined yet coordinated bodily sensations. For humans who live in a social and cultural world, the development of perception, intellect, feeling, and emotion takes place through the assimilation of an extrinsic cultural heritage, and through the active mastery of technologies, 
symbols, knowledge, and language. Intentional social activity, social meanings, and symbols do not simply change the expression and meaning of biologically inherited emotions. Instead, social and cultural inheritance creates feeling and emotion through the organisation of bodily activity - the kinaesthetic bodily logos - in the processes reforming neurobiology in terms of dynamical brain systems that are shaped in ontogenetic development. Emotions are therefore recent in their origin, appearing differentially across cultures with the various social and historical expressions of what it is to be human. 


\section{References}

Bakhtin, M. M. (1990). Art and answerability: Early philosophical essays by M. M. Bakhtin (M. Holquist \& V. Liapunov, Eds.). Austin, TX: University of Texas Press. (Original work published 1920-1923).

Barbalet, J. M. (1998). Emotion, social theory, and social structure: A macrosociological approach. Cambridge, UK: Cambridge University Press.

Bruner, J. (1987). Prologue to the English edition. In R. W. Rieber \& A. S. Carton (Eds.), The collected works of L. S. Vygotsky: Volume 1, Problems of general psychology (pp. 1-16). New York, NY: Plenum Press.

Burkitt, I. (2014). Emotions and social relations. London, UK: Sage.

Choudhury, S. \& Slaby, J. (Eds.) (2012). Critical neuroscience: A handbook of the social and cultural contexts of neuroscience. Chichester, UK: Wiley-Blackwell.

Clark, A. (2008). Supersizing the mind: Embodiment, action, and cognitive extension. Oxford, UK: Oxford University Press.

Colombetti, G. (2014). The feeling body: Affective science meets the enactive mind. Cambridge, MA: MIT Press.

Cromby, J. (2007). Towards a psychology of feeling. International Journal of Critical Psychology, 21, 94-118.

Damasio, A. R. (1995). Descartes' error: Emotion, reason and the human brain. London, UK: Picador. 
Damasio, A. R. (2000). The feeling of what happens: Body, emotion and the making of consciousness. London, UK: Vintage.

Damasio, A. R. (2004). Looking for Spinoza: Joy, sorrow and the feeling brain. London, UK: Vintage.

Dewey, J. (1958). Experience and nature (2nd ed.). New York, NY: Dover Publications. (Original work published 1929).

Fleer, M., González Rey, F. \& Veresov, N. (Eds.) (2017). Perezhivanie, emotions and subjectivity: Advancing Vygotsky's legacy. Singapore: Springer.

Freeman, W. J. (2000). Emotion is essential to all intentional behaviour. In M. D. Lewis \& I. Granic (Eds.), Emotion, development, and self-organization: Dynamic systems approaches to emotional development (pp. 209-235). Cambridge, UK: Cambridge University Press.

Gergen, K. J. (2009). Relational being: Beyond self and community. Oxford, UK: Oxford University Press.

González Rey, F. (2012). Advancing on the concept of sense: Subjective sense and subjective configurations in human development. In M. Hedegaard, A. Edwards, \& M. Fleer (Eds.), Motives in children's development: Cultural-historical approaches (pp. 45-62). New York, NY: Cambridge University Press.

Hochschild, A. R. (1983). The managed heart: Commercialization of human feeling. Berkeley, CA: University of California Press.

Holodynski, M. (2013). The internalization theory of emotions: A cultural 
historical approach to the development of emotions. Mind, Culture, and Activity, 20, 4-38. doi: 10.1080/10749039.2012.745571

James, W. (1971). What is an emotion? In G. W. Allen (Ed.), A William James reader (pp. 41-57). Boston, MA: Houghton Mifflin. (Original work published 1884).

Kitayama, S. \& Uskul, A. K. (2011). Culture, mind, and the brain: Current evidence and future directions. Annual Review of Psychology, 62, 419-449. doi: 10.1146/annurev-psych-120709-145357

Lang, P. J. (2014). Emotion's response patterns: The brain and the autonomic nervous system. Emotion Review, 6, 93-99. doi: 10.1177/1754073913512004

LeDoux, J. (1999). The emotional brain: The mysterious underpinnings of emotional life. London, UK: Phoenix.

Leontyev, A. N. (1972). The problem of activity in psychology. Soviety Psychology, 9, pp. 4-33. doi: 10.2753/RP01061-040513024

Leontyev, A. N. (1978). Activity, consciousness and personality. (M. J. Hall, Trans.). Englewood Cliffs, NJ: Prentice Hall.

Leontyev, A. N. (1981). Problems of the development of the mind. Moscow, RU: Progress Publishers.

Luria, A. R. (1932). The nature of human conflicts or emotion, conflict and will: An objective study of disorganisation and control of human behaviour. (W. Horsley Gantt, Trans \& Ed.) New York, NY: Grove Press. 
Luria, A. R. (1966). Human brain and psychological processes. (B. Haigh, Trans.) New York, NY: Harper and Row.

Luria, A. R. (1973). The working brain: An introduction to neuropsychology. (B. Haigh, Trans.) New York, NY: Basic Books.

Luria, A. R. (1981). Language and Cognition. New York, NY: John Wiley \& Sons.

Mahn, H. \& John-Steiner, V. (2002). The gift of confidence: A Vygotskian view of emotions. In G. Wells \& G. Claxton (Eds.), Learning for life in the $21^{\text {st }}$ century: Sociocultural perspectives on the future of education (pp. 46-58). Oxford, UK: Blackwell.

Marx, K. \& Engels, F. (1970) The German Ideology. London, UK: Lawrence \& Wishart. (Original work published 1846).

Noë, A. (2004). Action in perception. Cambridge, MA: MIT Press.

Norman, G. J., Berntson, G.G., \& Cacioppo, J. T. (2014). Emotion, somatovisceral afference, and autonomic regulation. Emotion Review, 6, 113-123. doi: $10.1177 / 1754073913512006$

Pessoa, L. (2008). On the relationship between emotion and cognition. Nature Reviews Neuroscience, 9, 148-158. doi: 10.1038/nrn2317

Ratner, C. (2000). A cultural-psychological analysis of emotions. Culture \& Psychology, 6, 5-39. doi: 10.1177/1354067X0061001

Rose, S. (2005). Lifelines: Life beyond the gene. London, UK: Vintage. 
Rose, S. (2006). The 21 st-century brain: Explaining, mending and manipulating the mind. London, UK: Vintage.

Roth, W-M. (2007). Emotion at work: A Contribution to third-generation cultural-historical activity theory. Mind, Culture, and Activity, 14, 40-63. doi: $10.1080 / 10749030701307705$

Sartre, J-P. (1965). Nausea (R. Baldick, Trans.). Harmondsworth, UK: Penguin. (Original work published 1938).

Saussure, F. de (1974). Course in general linguistics (W. Baskin, Trans.). London, UK: Fontana.

Vygotsky, L. S. (1987). Thinking and speech. In R. W. Rieber \& A. S. Carton (Eds.), The collected works of L. S. Vygotsky: Volume 1, Problems of general psychology (N. Minick, Trans., pp. 39-285). New York, NY: Plenum Press. (Original work published 1934).

Williams, R. (1977). Marxism and literature. Oxford, UK: Oxford University Press. 